\title{
Transnasal Endoscopic Approach for the Treatment of Medial Orbital Wall Fractures
}

\author{
Anna Bonsembiante, Luisa Valente', Andrea Ciorba, Manlio Galiè', Stefano Pelucchi \\ Department of ENT, ENT Unit, University Hospital of Ferrara, 'Department of Cranio-Maxillofacial Surgery, Unit of Cranio-Maxillofacial Surgery, \\ University Hospital of Ferrara, Ferrara, Italy
}

\section{Abstract}

The aim of this study is to report a case series of blowout fractures of the medial orbital wall that were treated endoscopically. Isolated fractures of the medial orbital wall are uncommon and can be asymptomatic. Various surgical methods for repairing medial orbital wall fractures have been described. The standard approach for the treatment of medial orbital wall fractures is the transcutaneous approach or the transconjunctival with retrocaruncular approach. In the last years, the attention on the use of minimally invasive techniques such as transnasal endoscopic approach is growing. This was a retrospective study of six cases completely managed endoscopically. In the presented case series, the endoscopic endonasal approach represented a safe and effective procedure for the reduction of medial wall orbital fractures.

Keywords: Blowout fracture, endoscopic approach, medial wall orbital wall fractures, orbital reconstruction

\section{INTRODUCTION}

Since 1921, the standard surgical approach for the treatment of medial wall orbital fractures has been the transcutaneous approach (medial canthal incision or Lynch incision approach ${ }^{[1]}$ ), first described by Lynch. ${ }^{[2]}$ Later, different approaches have been reported, such as transcaruncular approach, transconjunctival incision, and inferior or superior eyelid incision. ${ }^{[3,4]}$ Major drawbacks of these techniques are the esthetic outcome and the limited exposure of the fracture site.

The first endoscopic endonasal surgical approach for the treatment of medial wall orbital fractures was described in 1991 by Yamaguchi. ${ }^{[3]}$ Since its introduction, the endoscope has become an indispensable instrument for endonasal surgery. ${ }^{[4]}$ Nowadays, this surgical treatment can be performed under local or general anesthesia, depending on fracture and patient status. ${ }^{[5]}$

The aim of this study is to describe the surgical outcome of blowout fractures of the medial orbital wall treated endoscopically at our university settings.

\section{Case Series}

From October 2017 to 2018, six patients affected by blowout fractures of the medial orbital wall were treated endoscopically, at our university settings.

\begin{tabular}{|l|l|}
\hline \multicolumn{3}{|c|}{ Access this article online } \\
\hline Quick Response Code: & Website: \\
\hline & www.amsjournal.com \\
\hline
\end{tabular}

The study was conducted retrospectively and in compliance with the Helsinki declaration; the research did not affect the patient care in any way, because only patient data were retrieved and reviewed. All patients gave their written consent to undergo surgery and to participate in the study, according to the Italian laws.

Patients were, one African and three Caucasian patients, diagnosed as isolated medial orbital fractures, and two Caucasian patients were diagnosed as medial and inferior orbital wall fracture. Five cases were right orbit fractures and one was left. Three (50\%) patients were male and three $(50 \%)$ were female; the age range was 22-63 years (average age of 48.2 years). The incidence was highest between the fourth and the sixth decades. In three (50\%) cases, the fracture was caused by accidental trauma; in two (33\%) cases, it was by violent assault and in one (17\%) case by a traffic accident. Of six patients, four $(66 \%)$ had diplopia and one patient also

Address for correspondence: Dr. Luisa Valente, Unit of Cranio-Maxillofacial Surgery, University Hospital of Ferrara, Via Aldo Moro, 8, 44122 Ferrara, Italy. E-mail: luisavalente@outlook.it

This is an open access journal, and articles are distributed under the terms of the Creative Commons Attribution-NonCommercial-ShareAlike 4.0 License, which allows others to remix, tweak, and build upon the work non-commercially, as long as appropriate credit is given and the new creations are licensed under the identical terms.

For reprints contact: reprints@medknow.com

How to cite this article: Bonsembiante A, Valente L, Ciorba A, Galiè M, Pelucchi S. Transnasal endoscopic approach for the treatment of medial orbital wall fractures. Ann Maxillofac Surg 2019;9:411-4. 
had enophthalmos. All patients showed periorbital edema and ecchymosis; in two cases, there was evidence of medial rectus muscle involvement at the computed tomography (CT) scans [Table 1].

All patients underwent a complete otolaryngologic examination, an ophthalmologic and orthoptic examination, and a maxillofacial CT scan to evaluate the fracture site and to plan the surgical approach [Figure 1 and Table 2].

All patients were informed of the potential risks and benefits of all treatment options and were treated by an endoscopic approach.

All the procedures were performed under general anesthesia by means of a $4-\mathrm{mm}, 0^{\circ}-30^{\circ}$ endoscopy. A solution of lidocaine and adrenaline is usually injected into the middle turbinate, uncinate process, and eventually septum. A horizontal incision is performed over the uncinate process, allowing a better exposition, and it is then excised to access the ethmoid bone. If necessary, ethmoidectomy is performed to clearly delineate the fracture site and eventually the herniated orbital tissue. It is important not to remove or injure the herniated orbital tissue: it can occur depending on the time lapse between the fracture onset and the surgical treatment, as the herniated orbital tissue can adhere to the ethmoid sinus mucosa. In these cases, gently compressing the orbit during the surgery can help to stretch out the orbital tissue and to carefully separate it and preserve it from surgical damages. ${ }^{[6,7]}$ In the presented series, there were no adherences between the herniated orbital tissues and the ethmoidal mucosae in any case.

In order to reconstruct the orbital walls, different materials, both autologous or synthetic, can be used. ${ }^{[8]}$ In the presented series [Table 3 and Figure 2], MEDPOR ${ }^{\circledR}$ was used in one case and then stabilized with fibrin glue and soft nasal packing $\left(\right.$ Kennedy ${ }^{\circledR}$ ). Polydioxanone (PDS) was used in two cases: one was then stabilized with fibrin glue and Merocel ${ }^{\circledR}$ $10 \mathrm{~cm}$ packing and PureRegen ${ }^{\circledR}$; another case was stabilized with medium turbinate split and PureRegen ${ }^{\circledR}$, no nasal packing in this case. Autologous materials were used in the remaining three cases: ethmoid bone fragment was used in one case, then stabilized with fibrin glue and Meroce $^{\circledR} 8 \mathrm{~cm}$ packing and PureRegen; vomer bone fragment was utilized in another case and stabilized with fibrin glue and medium turbinate mucosal flap and soft nasal packing $\left(\right.$ Kennedy $\left.^{\circledR}\right)$; septal cartilage was used in the last one case and then stabilized with fibrin glue and PureRegen ${ }^{\circledR}$ with no nasal packing.

All the patients retained nasal packing for $48 \mathrm{~h}$ after surgery.

The mean time of hospitalization was three days (from two to five days); one patient had a longer hospital stay due to other concomitant pathologies. All patients were given antibiotics for 5 days (amoxicillin-clavulanate).

All patients were followed up after surgery up to six months on average, by periodic ear-nose-throat and/or maxillofacial evaluations (ophthalmologic evaluation and control CT scans were also prescribed in the selected cases) [Figure 3].

No late complications occurred.

\section{Discussion}

Indication for surgical intervention of medial orbital wall fractures is functional and/or anatomical and includes ${ }^{[3]}$ enophthalmos $>2 \mathrm{~mm}$, eye movement limitation, persistent diplopia, medial rectus muscle entrapment at CT scans, and the presence of an orbital defect (larger than $2 \mathrm{~cm}^{2}$ and association with at least $3 \mathrm{~mm}$ of displacement) that could cause secondary enophthalmos. ${ }^{[9-12]}$ All our patients presented an anatomical and/or functional indication and were all treated endoscopically. Among the different surgical strategies available for the treatment of medial wall blowout fractures, ${ }^{[13,14]}$ the transcutaneous approach was the first described. In this case, the incision is made over the medial canthal area followed by dissection of both periosteum and medial canthal tendon, and the herniated orbital tissue can then be replaced into the orbital cavity. The medial wall defect can be usually restored by a bovine pericardium graft. ${ }^{[15]}$ This technique usually offers a good exposition of the fracture site, but leaves visible cutaneous scars; another drawback is the possible injury of the medial canthal tendon, lacrimal apparatus, and supratrochlear nerve. ${ }^{[16]}$ In the transcaruncular approach, the incision is performed between the caruncle and plica semilunaris of conjunctiva; then carefully dissecting the soft tissue, the periosteum of the medial wall is reached. Finally, subperiosteal dissection is made until the area of the fracture is well detected. It is described as a safe and fast surgical approach, ${ }^{[16]}$ but the surgical field is restricted, and this implicates that implants cannot be inserted deeply into the posterior edge of the fornix; moreover, corneal abrasions or injury to the lacrimal drainage system as complication of

\begin{tabular}{|c|c|c|c|c|c|c|c|}
\hline Case & Sex & Type of fracture & Side & Age (years) & Etiology & MRM involvement & Clinic \\
\hline 1 & Female & Medial BOF & Right & 63 & Accidental trauma & Yes & 1 \\
\hline 2 & Male & Medial BOF & Right & 61 & Traffic accident & No & $\mathrm{D}$ \\
\hline 3 & Female & Medial BOF & Right & 22 & Violent assault & Yes & $\mathrm{D}$ \\
\hline 4 & Female & Medial + inferior BOF & Right & 54 & Accidental trauma & No & / \\
\hline 5 & Male & Medial BOF & Right & 47 & Accidental trauma & Yes & $\mathrm{D}+\mathrm{E}$ \\
\hline 6 & Male & Medial + inferior BOF & Left & 42 & Violent assault & No & $\mathrm{D}$ \\
\hline
\end{tabular}

$\mathrm{BOF}=\mathrm{Blowout}$ fracture; $\mathrm{MRM}=$ Medial rectus muscle; $\mathrm{D}=$ Diplopia; $\mathrm{E}=$ Enophthalmos; /=None 
Bonsembiante, et al.: Transnasal endoscopic approach for the treatment of medial orbital wall fractures

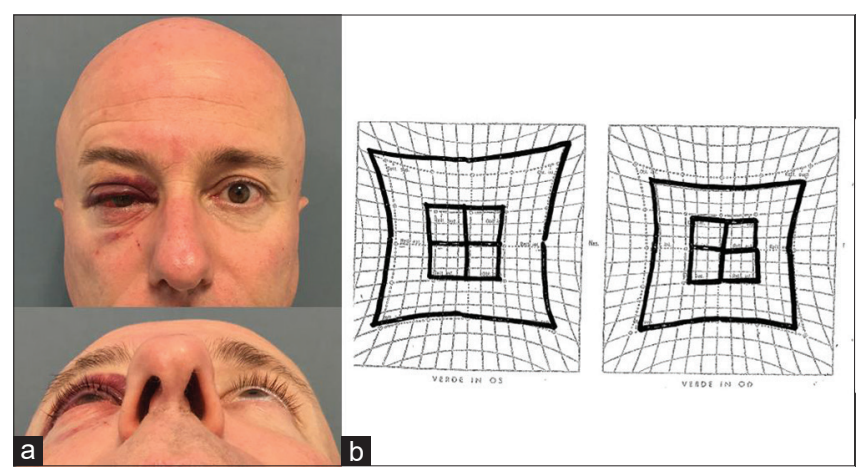

Figure 1: Case no 5: (a) Preoperative frontal and submental view; (b) preoperative Hess-Lancaster screen test
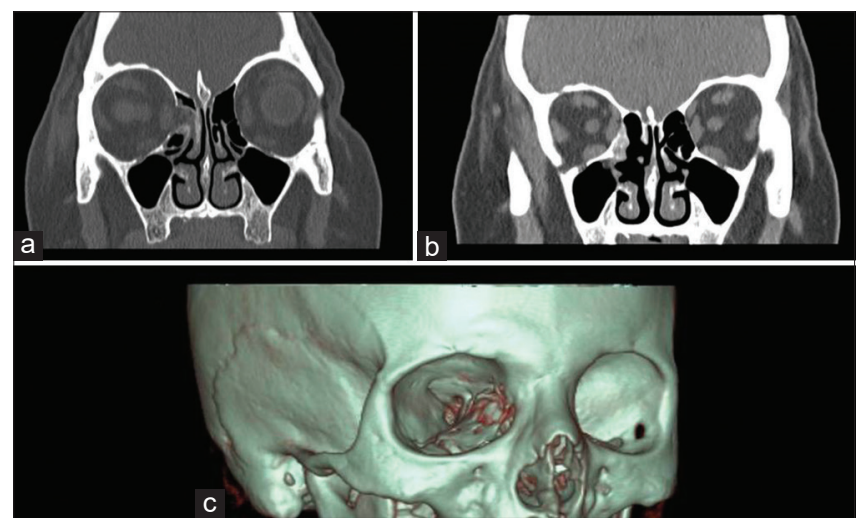

Figure 2: Case no 1: (a) Right medial wall blowout fracture before treatment; (b) right medial blowout fracture after surgical treatment; (c) three-dimensional reconstruction of the right medial blowout fracture after surgical treatment

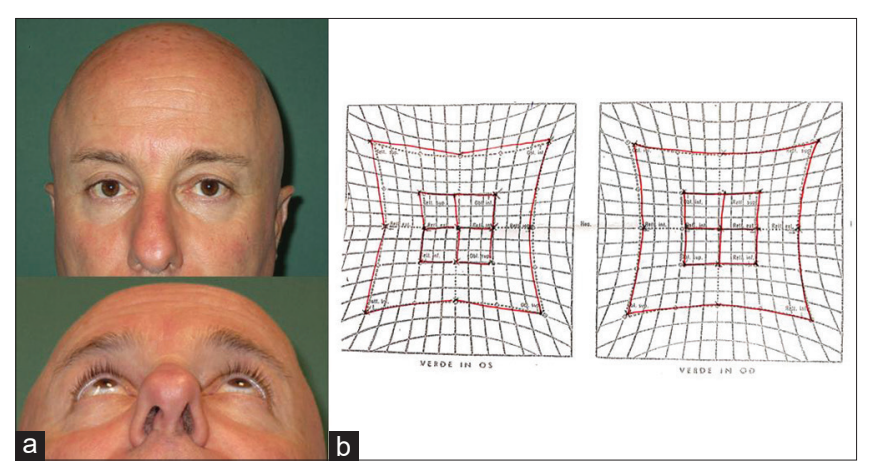

Figure 3: Case no 5: (a) Postoperative frontal and submental view; (b) postoperative Hess-Lancaster screen test

the surgical incision and implant displacement, protrusion, absorption, and infections have been reported. ${ }^{[2,13,16]}$

The endoscopic orbital approach has been reported by many authors as one of the most feasible treatments for medial orbital wall fractures. ${ }^{[3,5]}$ It allows a good visualization of the fracture site, lowering the risk of conjunctival lesions, optical nerve traction, and esthetic scarring. Major reported drawback is the difficulty in managing the reconstruction phase. ${ }^{[4]}$ Complications such as infection of the surgical site or sinusitis caused by the obstruction of the sinus ostium

\begin{tabular}{|c|c|c|c|}
\hline Case & Side of fracture & $\begin{array}{c}\text { Right eye } \\
\text { protrusion (mm) }\end{array}$ & $\begin{array}{c}\text { Left eye } \\
\text { protrusion (mm) }\end{array}$ \\
\hline 1 & Right & 20 & 21 \\
\hline 2 & Right & 25 & 24 \\
\hline 3 & Right & 20 & 19 \\
\hline 4 & Right & 18 & 17 \\
\hline 5 & Right & 20 & 21 \\
\hline 6 & Left & 21 & 24 \\
\hline
\end{tabular}

can be avoided by a careful insertion of a silastic sheet, the early removal of nasal tampons, and the administration of antibiotics. $^{[17]}$

The ideal material for orbital reconstruction remains controversial: it should be biocompatible, readily available, strong enough to provide orbital support, easy to manipulate and insert, and radiopaque. ${ }^{[13,18]}$ Most commonly used are a Silastic ${ }^{\circledR}$ or Medpor ${ }^{\circledR}$ sheet, both designed to fit the ethmoidectomy cavity and to exclude the ostial drainage of the frontal sinus and maxillary sinus. ${ }^{[19]}$ Porous polyethylene $\left(\right.$ Medpor $^{\circledR}$ ) is an inert and nonabsorbable polymer developed to facilitate tissue ingrowth and reduce foreign body reactions and capsule-correlated complications. ${ }^{[1,16]}$

Silicone sheets (Silastic $($ ) include low cost, flexibility, ease of handling, and adequate support; however, it must be mentioned its lack of rigidity and the possibility of fibrous capsule formation, infections, and extrusion. ${ }^{[18,20]}$ PDS is a colorless semicrystalline polymer. ${ }^{[18]}$ It has similar properties to silicone sheets. Autologous reconstruction materials include bone, cartilage, fascia lata, and periosteum. Their use is preferred due to their availability, mechanical properties, and low risk of infection or scarring. However, they have unpredictable resorption rates and provide suboptimal volume correction; in addiction, it is quite difficult to forge in complex shapes. ${ }^{[1,16]}$

In the presented series, there were no substantial differences in the use of autologous or synthetic materials on surgical time, hospital staying, and early complication.

The nasal packing can be managed in different ways: from the removal of the day after the intervention to the removal of 3 or 4 weeks under local anesthesia ${ }^{[4,21]}$ and till no needs of secondary procedures in case of use of absorbable packing materials. $^{[22]}$

No differences were found in our study between the various methods of nasal packing used.

In conclusion, the endoscopic endonasal approach represented a safe and effective procedure for the reduction of medial wall orbital fractures and also in the presented case series.

\section{Declaration of patient consent}

The authors certify that they have obtained all appropriate patient consent forms. In the form the patient(s) has/have 
Bonsembiante, et al.: Transnasal endoscopic approach for the treatment of medial orbital wall fractures

\begin{tabular}{|c|c|c|c|c|}
\hline Case & Type of fracture & Reconstruction materials & Nasal packing & Stabilization and medication \\
\hline 1 & Medial BOF & Vomer bone fragment + turbinate mucosal flap & Soft nasal packing $\left(\right.$ Kennedy $\left.^{\mathbb{}}\right), 48 \mathrm{~h}$ & Fibrin glue \\
\hline 2 & Medial BOF & Ethmoid bone fragment & Ivalon $8 \mathrm{~cm}, 8 \mathrm{~h}$ & Fibrin glue, PureRegen ${ }^{\circledR}$ \\
\hline 3 & Medial BOF & Vomer bone fragment + septal cartilage & No nasal packing & Fibrin glue, PureRegen ${ }^{\circledR}$ \\
\hline 4 & Medial + inferior BOF & PDS + turbinate split & No nasal packing & Fibrin glue, PureRegen ${ }^{\circledR}$ \\
\hline 5 & Medial BOF & Medpor $^{\mathbb{B}} 0,7$ & Soft nasal packing $\left(\right.$ Kennedy $\left.^{\mathbb{\circledR}}\right), 48 \mathrm{~h}$ & Fibrin glue \\
\hline 6 & Medial + inferior BOF & PDS & Merocel $8 \mathrm{~cm}, 48 \mathrm{~h}$ & Fibrin glue \\
\hline
\end{tabular}

$\mathrm{BOF}=$ Blowout fracture; PDS=Polydioxanone

given his/her/their consent for his/her/their images and other clinical information to be reported in the journal. The patients understand that their names and initials will not be published and due efforts will be made to conceal their identity, but anonymity cannot be guaranteed.

\section{Financial support and sponsorship}

Nil.

\section{Conflicts of interest}

There are no conflicts of interest.

\section{RefERENCES}

1. Totir M, Ciuluvica R, Dinu I, Careba I, Gradinaru S. Biomaterials for orbital fractures repair. J Med Life 2015;8:41-3.

2. Procacci P, Trevisiol L, Nocini PF, Favero V, D'Agostino A. Modified technique for endoscopic endonasal reduction of medial orbital wall fracture using an absorbable packing. Oral Maxillofac Surg 2017;21:91-8.

3. Sanno T, Tahara S, Nomura T, Hashikawa K. Endoscopic endonasal reduction for blowout fracture of the medial orbital wall. Plast Reconstr Surg 2003;112:1228-37.

4. Copelli C, Manfuso A, d'Ecclesia A, Catanzaro S, Cassano L, Pederneschi N, et al. Endoscopic transnasal approach and intraoperative navigation for the treatment of isolated blowout fractures of the medial orbital wall. J Craniomaxillofac Surg 2015;43:1974-8.

5. Felix V, Veerasigamani N. Endoscopic endonasal approach of blow out fracture reduction- A novel technique. J Clin Diagn Res 2017;11:MD06-MD08.

6. Thiagarajah C, Kersten RC. Medial wall fracture: An update. Craniomaxillofac Trauma Reconstr 2009;2:135-9.

7. Patnaik VV, Bala S, Singla RK. Anatomy of the bony orbit - Some applied aspects. J Anat Soc India 2001;50:59-67.

8. Takahashi Y, Nakakura S, Sabundayo MS, Kitaguchi Y, Miyazaki H, Mito $\mathrm{H}$, et al. Differences in common orbital blowout fracture sites by age. Plast Reconstr Surg 2018;141:893e-901.

9. Chi MJ, Ku M, Shin KH, Baek S. An analysis of 733 surgically treated blowout fractures. Ophthalmologica 2010;224:167-75.
10. de Silva DJ, Rose GE. Orbital blowout fractures and race. Ophthalmology 2011;118:1677-80.

11. Degala S, Shetty SK, Biddappa L. Reconstruction of post-traumatic internal orbital wall defects with titanium mesh. J Maxillofac Oral Surg 2013;12:418-23

12. Clauser L, Galiè M, Pagliaro F, Tieghi R. Posttraumatic enophthalmos: Etiology, principles of reconstruction, and correction. J Craniofac Surg 2008;19:351-9.

13. Han K, Choi JH, Choi TH, Jeon SY, Kim JS, Kim NG, et al. Comparison of endoscopic endonasal reduction and transcaruncular reduction for the treatment of medial orbital wall fractures. Ann Plast Surg 2009;62:258-64

14. Clauser L, Galiè M, Mandrioli S, Sarti E. Severe panfacial fracture with facial explosion: Integrated and multistaged reconstructive procedures. J Craniofac Surg 2003;14:893-8.

15. Pagnoni M, Giovannetti F, Amodeo G, Priore P, Iannetti G. Endoscopic endonasal versus transfacial approach for blowout fractures of the medial orbital wall. J Craniofac Surg 2015;26:e247-9.

16. Kim YH, Park Y, Chung KJ. Considerations for the management of medial orbital wall blowout fracture. Arch Plast Surg 2016;43:229-36.

17. Jin HR, Shin SO, Choo MJ, Choi YS. Endonasal endoscopic reduction of blowout fractures of the medial orbital wall. J Oral Maxillofac Surg 2000;58:847-51

18. Colletti G, Pipolo C, Lozza P, Felisati G, Allevi F, Biglioli F, et al. Orbital medial wall fractures: Purely endoscopic endonasal repair with polyethylene implants. Clin Otolaryngol 2018;43:396-8.

19. Chung KJ, Lim JH, Kim TG, Lee JH, Kim YH. Correction of medial blowout fractures according to the fracture types. Ann Plast Surg 2016;76:46-50.

20. Thomas V, Zhang X, Vohra YK. A biomimetic tubular scaffold with spatially designed nanofibers of protein/PDS bio-blends. Biotechnol Bioeng 2009;104:1025-33.

21. Jeon SY, Kim C, Ma Y, Hwang E. Microsurgical intranasal reconstruction of isolated blowout fractures of the medial orbital wall. Laryngoscope 1996;106:910-3.

22. We J, Kim Y, Jung T, Bae K, Cho J, Kwon J. Modified technique for endoscopic endonasal reduction of medial orbital wall fracture using a resorbable panel. Ophthalmic Plast Reconstr Surg 2009;25:303-5. 